\title{
CONFLITO DE IDENTIDADE NACIONAL DE CABO VERDE
}

\author{
Ratsiferana Macrina Alfama PEREIRA*
}

\author{
*Centro de Ciências Humanas, Letras e Artes, Núcleo de Direitos Humanos e Cidadania -UFPB, \\ mashinecv@yahoo.com.br
}

Recebido em: 21/05/2014 - Aprovado em: 15/09/2014 - Disponibilizado em: 15/12/2014

\begin{abstract}
Resumo:
O presente artigo busca entender as características jurídicas de Cabo Verde face ao reconhecimento do multiculturalismo. Tentou-se através de alguns dados bibliográficos conferir a presença de lacunas dentro do processo jurídico comparado ao sistema empírico e revelar alguns desafios que carecem de ser enfrentados para melhorar a eficiência do processo jurídico perante o multiculturalismo.
\end{abstract}

Palavra-chave: identidade, reconhecimento do multiculturalismo.

\section{Introdução}

A política do reconhecimento toma como ponto central para a reflexão e a realização da justiça, a possibilidade de respeito ás diferenças culturais. A injustiça, como afirma Axel Honneth, sociólogo e filósofo de Frankfurt, que se debruçou sobre a formulação da teoria critica do reconhecimento com contribuições decisivas, é uma condição de desrespeito que estaria dada na ausência de uma eticidade reguladora (HONNETH, 1995). O pressuposto, como afirma Honneth, é que o paradigma da justiça social tome a questão do reconhecimento como seu centro, em que o fundamental seria a realização de uma política da diferença que, por sua vez, estabeleceria as condições estruturais para a igualdade. Nessa chave da justiça como teoria social, as questões culturais teriam precedência ontológica sobre as condições estruturais do mundo material, em que as questões de justiça básica seriam, por definição, questões identitárias e centradas na busca das condições do autorrespeito.

A democracia constitucional, segundo Habermas tem o papel de mediar conflitos através do respeito pelo direito dos outros, mas para isso há os guiões positivos e os guiões negativos.

“os sujeitos humanos
dependem constitutivamente
de uma aceitação em termos
normativos por parte dos
outros para formar as suas
identidades, na medida em que
eles só podem afirmar as suas
pretensões de ordem prática e


objetiva com base na reação positiva dos seus semelhantes. (Honneth, 1995: 226).

Honneth formula as suas ideias seguindo uma visão habermiano e considera as lutas coletivas como casos de relevância para conflitos que se tornam muitas vezes produtivos.

Cabo Verde, país situado á $650 \mathrm{~km}$ do Senegal fez a sua constituição da identidade nacional ao reflexo das culturas: europeia e africana. Colônia portuguesa até 1975 foi povoado também pelos escravos emanados da costa Africana, de modo mais preciso da Guiné-Bissau. A fusão cultural que deu "vida" á mestiçagem dos caboverdianos teve uma repercussão positiva por parte dos intelectuais do referido país, no que dizia respeito á constituição de uma unidade nacional mesmo antes da implantação de um Estado nacional.

\section{Contexto histórico}

Segundo Charles Taylor a identidade significa aquilo que somos "de onde nós provimos." É o ambiente no qual os nossos gostos, desejos, opiniões e aspirações fazem sentido. "A descoberta da minha identidade é uma negociação entre eu e os outros, ou seja, a minha identidade depende decisivamente das minhas reações dialógicas com os outros" (TAYLOR, 1994, p. 54).

Sob o olhar da política de reconhecimento, o referido autor refina o seu pensamento afirmando que a exigência do reconhecimento no multiculturalismo adquire uma certa premência devido á suposta relação entre o reconhecimento e a identidade, traduzindo assim, na maneira como o próprio individuo se define.

Cabo Verde que recebeu influências culturais de dois povos basicamente heterogêneos se define em sua essência como um ser ou mesmo um povo mestiço. Enquanto no Brasil a ideologia da mestiçagem, como definidor da identidade nacional, não exclui que determinados grupos possam ser considerados italianos, poloneses, alemãs por sua ascendência europeia, ou ainda afrodescendente pela ascendência africana, aqui todos os cabo-verdianos seriam, por excelência, apenas mestiços. Mas, como a alegada nação lida com a situação dessa fusão de culturas?

A constituição da Republica de Cabo Verde imprime lei fundamental que regula os deveres dos cidadãos. A lei constitucional é revista pelos deputados da Nação.

Cabo Verde começou a sentir "a fragrância" da sua independência a partir do final do sec. XIX e início do 
sec. XX, depois da Revolta dos Cravos em Portugal que se deu a 25 de abril de 1974. Esta fase estratégica foi o marco final do regime de Salazar e do Terceiro Império Português. Não só os portugueses como os ex-colônias portuguesas também tiveram início a uma nova história. Começaram então, amplas campanhas e movimentos políticos na Praia (capital do país) e no Mindelo com a libertação a 1 de Maio de 1974, dos presos políticos caboverdianos e angolanos no campo de Tarrafal na ilha de Santiago.

O PAIGC (Partido Africano de Independência de Cabo Verde e GuinéBissau) se tornou como o único partido que lutou junto ao movimento da libertação nacional do povo caboverdiano apoiando-se ao pensador e líder Amilcar Cabral.

"Amilcar Cabral era poeta, agrônomo, teórico e líder político da revolução anticolonial da Guiné-Bissau e de Cabo Verde, "o pedagogo político-cultural" que ensinava o "aprendizado da liberdade", como diz o escritor e redator da revista Presénce Africaine." (Villen, 2013, p. 14)

Cabral nasceu em 1924 na Guiné Bissau, mas viveu grande parte da sua vida em Cabo Verde e Portugal onde realizou a sua formação.
As jornadas e as movimentações políticas tiveram seu auge no período antes da constituição do Governo de Transição do Estado de Cabo Verde com a neutralização política e prisão de alguns adversários. A 5 de Julho de 1975, o presidente da Assembleia Nacional Popular, Abílio Duarte, proclama a República de Cabo Verde, livre, independente e soberana, e os deputados eleitos por sufrágio universal utilizariam o prazo de três meses após a independência para aprovação de uma Constituição política para o tal Estado Soberano. Porém, PAIGC é um partido binacional que governava Cabo Verde e Guiné-Bissau. Enquanto projetavam o sonho de Amilcar Cabral de uma pátria africana binacional, Guiné-Bissau sofre golpe de Estado e a 14 de Novembro de 1980, os dois países se desfazem do laço político. Então, Cabo Verde monta um regime político do partido único e nos primeiros cinco anos da independência tem uma ausência de uma Constituição formal. Entretanto, a LOPE (Lei da Organização Política do Estado) adotada desde 5 de julho de 1975 serviu como Lei Fundamental do país.

Nesta óptica, serviram tanto esse programa (aliás, omisso quanto à questão do regime de 
partido único, mas muito detalhado quanto ao modelo de sociedade, ao sistema de governo e ao modelo económico-social, às funções e tarefas do Estado, aos direitos e deveres fundamentais de natureza pessoal, política, económica, social e cultural dos cidadãos dos Estados soberanos e independentes da Guiné-Bissau e de Cabo Verde), como as resoluções dos competentes órgãos partidários dirigentes, quer os supranacionais quer os nacionais, como parâmetro de interpretação das normas jurídicas importadas do período colonial. (ALMADA, 2014).

A Constituição Política de 1980 consagra plena a democracia nacional revolucionária como práxis política e dominação oficial do regime autoritário do partido único implantado pela LOPE que se apresentava como fundada na soberania popular, como na democracia participativa.

A primeira constituição era composta por 96 artigos pela Assembleia Nacional Popular (ANP) elaborada por juristas. O golpe de Estado na Guiné-
Bissau pôs fim aos laços de união entre os dois países e Cabo Verde divulgaria a criação do PAICV em 1981, o que levou a revisão da constituição no mesmo ano. As adulterações aprovadas constavam a revogação do artigo $4^{\circ}$ : "Na Republica d Cabo Verde, o Partido Africano da Independência de Cabo Verde (PAICV) é a força politica dirigente da sociedade e do Estado". O multiculturalismo não constava no LOPE. O período de 1975 a 1990 Cabo Verde vivia em um regime de partido Estado, monolítico, centralizador e totalitário, pois dominava toda a sociedade onde o pluralismo não era benquisto; os cidadãos não podiam exercer, livre e efetivamente, direitos e liberdades fundamentais como as de expressão, de imprensa, de associação, de reunião, de manifestação e de greve; e além disso a Constituição não tinha garantias; algumas vezes, o Poder empregou violência contra os que ousavam divergir.

Entretanto, por ouro lado, o dialeto crioulo que surgiu da interação dos povos que habitaram Cabo Verde foi constantemente atacado no sec.XIX, uma vez que no colonialismo era proibido o uso do dialeto nas escolas e instituições. Após a independência, o documento "O Novo Ensino em Cabo Verde", do II Congresso do PAICV, 
citado pelo Ministério de Educação defendia a universalidade e a funcionalidade de educação em identidade cultural, com a perspectiva de valorizar a cultura da linguagem nativa.

A época do partido único tem o seu fim nas eleições eleitorais legislativas $\mathrm{e}$ presidenciais, autárquicas de 1991, onde surge o Movimento para a Democracia (MPD), conduzida por Carlos Veiga, como primeiro partido da oposição e tem uma vitória esmagadora, com maioria qualificada, da lista dos candidatos propostos. O MPD então projeta uma nova constituição com mudanças diversas tendo em conta as alterações politicas que se sucederam no país.

A 5 de agosto de 1992 foi aprovado pela Assembleia Nacional o novo texto da constituição com 56 votos a favor e 16 abstenções e nenhum voto contra. Em 1999 a revisão incidiu sobre o hino nacional que foi constitucionalizado; a oficialização da língua materna caboverdiana a ser promovida pelo Estado em paridade com a língua portuguesa; maior equidade de gênero no que diz respeito á participação política, entre outros.

Somente após a Constituição de 1992, Cabo Verde foi considerado como um país de Estado democrático e introduziu um novo olhar para sua identificação no que diz respeito aos símbolos nacionais do país como a Bandeira, o Hino e Armas. O Estado separou a Bandeira de Cabo Verde que era igual á do Paicv, e construiu também um novo hino para Cabo Verde uma vez que o país dividia o mesmo hino com a Guiné até então.

\section{O processo do multiculturalismo}

Cabo Verde em combate ao pensamento único ou regime único deu inicio ao seu processo pluralista em 1990 introduzindo uma sociedade livre de convivência pacata ou pacífica e de respeito entre os pensamentos díspares. Tornou-se, portanto caracterizado em um Estado de Direito Democrático onde não se pode falar em pensamento melhor que o outro, uma vez que todos são dignos de respeito.

Constata-se que a constituição caboverdiana de 1992, em seu preâmbulo, certifica a pluralidade da sociedade nacional,

Assumindo plenamente o princípio da soberania popular, o presente texto da Constituição consagra um Estado de Direito Democrático com um vasto catálogo de direitos, liberdades e garantias dos cidadãos, a concepção da 
dignidade da pessoa humana como valor absoluto e sobrepondo-se ao próprio Estado, um sistema de governo de equilíbrio de poderes entre os diversos órgãos de soberania, um poder judicial forte e independente, um poder local cujos titulares dos órgãos são eleitos pelas comunidades e perante elas responsabilizados, uma Administração Pública ao serviço dos cidadãos $\mathrm{e}$ concebida como instrumento do desenvolvimento e um sistema de garantia de defesa da Constituição característico de um regime de democracia pluralista. (CONSTITUIÇÃO DA REPÚBLICA DE CABO VERDE, 1992)

A mesma carta afiança respeito pela dignidade da pessoa humana e reconhece a inviolabilidade $\mathrm{e}$ inalienabilidade dos Direitos do Homem como fundamento de toda a comunidade humana, da paz e da justiça. Assegura também o reconhecimento à igualdade de todos os cidadãos perante a lei sem distinguir raça, religião, convicções politicas, sexo, etc. Mas, qual o limite ou até que ponto pode-se afirmar que essa constituição garante essa pluralidade, essa concepção multicultural?

No multiculturalismo coexistem diferentes culturas e tradições, simplesmente uma combinação de culturas, valores e visões de vida. Cabo Verde assume então as caraterísticas de um país baseado no multiculturalismo, como é de se notar que a constituição de 1992 acolhe, com abolição de pensamento único, pensamentos diversos sobre um determinado tema, isto quer dizer que se aproveita de diálogos (método do reconhecimento multicultural, segundo Charles Taylor) de culturas onde o resultado é uma convivência pacífica e positiva entre elas. Contudo, esse diálogo não pode ser onde se aceita tudo, mas onde se estabelecem critérios mínimos para o diálogo entre as culturas para que se possam referenciar os direitos humanos na concepção do multiculturalismo.

Diferentemente disso, multiculturalismo pode ser facetado no formato relativista ou universalista.

$\mathrm{O}$ enfoque relativista deixa lacuna no que tange aos critérios mínimos para o diálogo entre as culturas, ou seja, tudo é aceito ou tudo é correto, o julgamento interno do país, local ou mesmo do ambiente é mais vital do que o julgamento externo a esses ambientes. 
Cada cultura é livre para estabelecer seus próprios valores e direitos e não existe possibilidade de proteção externa dos direitos humanos nessa visão. Consoante estas asseverações, percebese $\log 0$ a inexistência dos direitos humanos universais.

A face universalista do multiculturalismo admite a proliferação e o desenvolvimento perante o diálogo de diferentes opiniões em que se estabelece um denominador mínimo, igual entre as partes para o começo do diálogo, isto é, valores universais ou ainda direitos humanos a serem respeitados. Nessa forma, o julgamento externo sobrepõe-se ao julgamento interno.

O universalismo do multiculturalismo traz uma base para o bom convívio entre os homens já que nele encontramos o caráter geral da Declaração Universal de Direitos Humanos.

A defesa dos direitos humanos universais seria deste modo, compatível com o pluralismo e com o multiculturalismo universalista, mas, totalmente inviável em um ambiente de multiculturalismo relativista. Muitas vezes, a visão desse universalismo traça marcas da convivência ocidental. Direitos Humanos e multiculturalismo pode nos conduzir para uma afirmação da dignidade humana.

A nível de Cabo Verde, o Relatório da Missão para avaliar a situação dos Direitos Humanos no dado país concluía que:

"Cabo Verde é uma nova
democracia, que em poucos
anos fez avanços significativos
com relação à proteção e
promoção dos direitos civis e
políticos. A promulgação da
Constituição de 1992, o
desenvolvimento de um
sistema multipartidário e o
fortalecimento da sociedade
civil têm contribuído para a
consolidação da democracia e a
proteção e promoção dos
direitos civis e políticos
fundamentais no país."

Assim como a Constituição brasileira de 1988, a Constituição de Cabo Verde também se perfilha a Declaração Universal dos Direitos Humanos, aprovada pela ONU em 1948.

O jurista Erik Jayme, professor da Universidade de Helderberg menciona que: 
O Direito faz parte da cultura geral. Tem raízes profundas na tradição, mas, também sofre influencias pelo desenvolvimento de nossa sociedade e da comunidade internacional. Dessa maneira, o nosso direito atual é em certa medida, reprodução de nossa cultura contemporânea, quer dizer da cultura pós-moderna. [Jayme, 2003 p.59 ]

A concepção do pluralismo admite não só a forma, mas também os estilos de vida, de fontes legislativas a regular o fato, pluralismo de sujeitos a proteger. É assim, a ideia de autonomia em escolher o seu próprio modo de vida. Jayme destaca que o pluralismo é um dos valores básicos da pós-modernidade que engloba o reconhecimento da diversidade de estilos de vida e a negação de uma pretensão universal à maneira própria de ser.

Deste modo, o pluralismo se manifesta na multiplicidade de fontes jurídicas a regular os conflitos sociais.

"Numa sociedade multicultural é fundamental respeitar a diversidade cultural e étnica, conhecer e dialogar com as diferentes culturas, sublinhar os seus aspetos positivos, desfazer preconceitos étnicos e raciais, dissipar estereótipos, e criar iguais oportunidades de integração social e de acesso aos bens essenciais para todos, independentemente das diferenças." (Nunes, 2004)

Cabo Verde, segundo Vera Duarte, expresidente da Comissão Nacional para os Direitos Humanos e a Cidadania, é um país democrático capaz de eliminar ou relativizar as diferenças existentes na sociedade considerando as meta da igualdade e dos direitos fundamentais. Nos dias atuais não se pode falar em igualdade sem incluir o tema da diversidade. A igualdade deve incluir a diferença e vice versa. Cabo Verde vem debatendo suas regras ainda de forma muito tímida, assim como começou o debate no Brasil. Cabo verde é um país multicultural que considera que todas as culturas e os outros são devidamente respeitados e que por isso não há ainda a necessidade de estabelecer regras de conduta para equilibrar as diferenças existentes na sociedade em questão.

Segundo Vera Candau, em seu capítulo do livro Direitos Humanos na Educação Superior, o multiculturalismo se divide em duas abordagens, a descritiva que abarca as particularidades sociais da atualidade dependendo do contexto histórico, político e socicultural e a outra abordagem prescritiva que traz o multiculturalismo dado a realidade, isto 
é, a maneira de atuar, de intervir, conceber políticas públicas. Como realça Candau, a abordagem descritiva intercultural considera $\mathrm{O}$ multiculturalismo aberto e interativo que acentua a interculturalidade que se torna mais adequada para a construção das sociedades, democráticas e inclusivas e que trabalham a educação em direitos humanos com visão de políticas de igualdade e de identidade.

$\mathrm{O}$ cabo verdiano tem uma radicalidade ao definir a sua identidade nacional talvez porque a sua mestiçagem surgiu não só de uma multiplicidade cultural, mas sim como produto acabado de uma fusão completa de duas culturas heterogêneas. O mestiço cabo-verdiano constitui a sua própria essência, define por si só o seu "eu" cabo-verdiano. Enquanto isso, no Brasil a mestiçagem reflete uma certa identidade, italiano, africano, alemão, isto é, a mestiçagem dá uma ideia mais relacionada de uma sociedade multirracial e multicultural.

\section{A crise indentitária dos cabo- verdianos}

Duas forças contrárias apontadas como a globalização e a identidade, lutam pela remodelação da vida dos caboverdianos. Não se fala aqui somente dos contactos com os turistas que se destinam para Cabo Verde, nem apenas dos cabo-verdianos da diáspora, mas também a inclusão do novo modo de viver, um apego ao mundo tecnológico desde a faixa de crianças chegando ás empresas ou instituições.

O Stuart Hall (2006) confirma em seu livro "A Identidade cultural na pósmodernidade", que a partir do iluminismo, o sujeito adquire a condição de um homem fragmentado, devido a uma crise de identidade. Por outro lado, Segmund Freud destaca o individuo entre $\mathrm{o}$ consciente $\mathrm{e} \quad \mathrm{o}$ inconsciente.

O homem parece buscar incessantemente a sua parte perdida ou deixada em qualquer lugar e nesse âmbito da busca do seu eu com seu outro, o encontro pode ser até conflituoso por causa da fragmentação da identidade e do descentramento do sujeito. O tecido do sujeito unificado está sendo desmanchado aos poucos na sociedade moderna no qual o individuo moderno incorpora novas identidades e se torna um individuo fragmentado. A isso, Stuart Hall (2006) deu o nome de "crise de identidade", o que sofre mudanças na estrutura e processos centrais das sociedades modernas em que os indivíduos se protegiam.

A construção da identidade segundo Hall dá a liberdade de escolha do 
individuo na medida em que ele pode escolher diversas identidades.

Pode-se afirmar de certa forma que Cabo Verde vive perante um sistema que lhe causa uma certa fragilidade em relação á sua afirmação de identidade. Se se reparar aos modos de viver dos cidadãos cabo-verdianos na atualidade percebe-se facilmente a valorização do turismo, a valorização dos estrangeiros e as influencias destes nas musicas locais, empreendimentos turísticos como os resorts na ilha do Sal e de Boavista. Tudo é mistura da Europa, Ásia, América e África.

Cabo Verde que construiu sua identidade na força das poesias dos claridosos como Baltasar Lopes, Corsino Fortes, hoje a sua identidade está recheada de questões, de indagações que neblina a sua identificação.

\section{CONCLUSÃO}

$\mathrm{O}$ presente artigo buscou entender as características jurídicas de Cabo Verde face ao reconhecimento do multiculturalismo. Tentou-se através de alguns dados bibliográficos conferir a presença de lacunas dentro do processo jurídico comparado ao sistema empírico e revelar alguns desafios que carecem de ser enfrentados para melhorar a eficiência do processo jurídico perante o multiculturalismo.

O caráter plural da cultura caboverdiana permite reforçar a ideia de que há um grande conjunto de direito que precisam, de fato, serem protegidos e reconhecidos.

O que não se pode aceitar, no entanto, é que a forma de satisfação, garantia ou exercício destes direitos se dê de uma única e exclusiva forma, qual seja pelos braços do Estado.

É de se notar que apesar de muito recente a caraterística jurídica pluralista vivenciada em Cabo Verde, o multiculturalismo vem sedo acatado de uma forma tímida nos debates. Isso acontece devido a lacunas percebidas no processo jurídico. O individuo caboverdiano tem caraterística do individuo multifacetário e o desafio do processo jurídico é exatamente acompanhar esse individuo no seu tempo e espaço. Há sim, que se enfrentar barreiras e construir melhorias.

\section{REFERENCIAS:}

ALMADA, José Luís Hopffer. Http://www.buala.org/pt/a-ler/dastragedias-historicas-do-povocaboverdiano-e-da-saga-da-suaconstituicao-e-da-sua-consolida. Disponível em: $<$ http://www.buala.org/pt/a-ler/dastragedias-historicas-do-povo- 
caboverdiano-e-da-saga-da-sua-

constituicao-e-da-sua-consolida>.

Acesso em: 20 jan. 2014.

Candau, Vera ( capitulo do livro: Direitos Humanos na Educação Superior: subsídios para a Educação em Direitos Humanos na Pedagogia. Editora

Habermas, Jürgen, "As lutas pelo reconhecimento no estado democrático constitucional", in Taylor et al., Multiculturalismo, Examin ando a política de reconhecimento, 1998

Honneth, Axel, The Fragmented World of Social: essays in social and political philosophy, N. York: SUNY Press, 199 5.

Jayme, Erik. Direito internacional privado e cultura pós-moderna. Cadernos do Programa Pós- Graduação em Direito, Porto Alegre, v. 1, n. 1, 2003.

Nunes, Thomaz(2004) Colaboração Escola-Familia Para uma escola culturalmente heterogênea, ACIME

REIS, Marcus V I Ní Cius. Multiculturalismo e Direitos Humanos. Disponível em: $<$ http://www.senado.gov.br/senado/spol /pdf/ReisMulticulturalismo.pdf>.

Acesso em: 10 jan. 2014.

Taylor, Charles

et

al., Multiculturalismo, Examinando a política de reconhecimento, Lisboa: Piaget, 199 8.
TAYLOR, C. 2001. Two Theories of Modernity. The International Scope Review , 3(5):1-9.

TAYLOR, C. 1994. La ética de la autenticidade . Barcelona, Paidós, 146 p. 